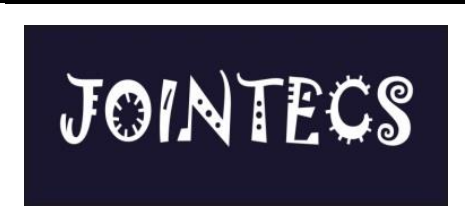

Vol. 5 No. 1 (2020) 49 - 54

\section{JOIN'TECS \\ (Journal of Information Technology and Computer Science)}

\author{
e-ISSN:2541-6448
}

\title{
Implementasi Encapsulation Jaringan Redudansi VLAN Menggunakan Metode Hot Standby Router Protocol (HSRP)
}

\author{
Hendy Dwi Haryoyudhanto ${ }^{1}$, Iskandar Fitri ${ }^{2}$, Andri Aningsih ${ }^{3}$ \\ Program Studi Teknik Informatika, Fakultas Teknologi Komunikasi dan Informasi, Universitas Nasional \\ 1hdharyoyudhanto@gmail.com, ${ }^{2}$ iskandar.fitri@civitas.unas.ac.id, ${ }^{3}$ andrianingsih@civitas.unas.ac.id
}

\begin{abstract}
Local Area Network is currently often used to minimize a public work, different network segmentation in a building requires attention in designing a network that has dense traffic and often occurs down and vails over on a network flow, certainly requires performance optimal and efficient network, by way of network encapsulation with one channel and dividing each network segmentation by VLAN. The purpose of this paper is to apply a design by optimizing a network using the network redundancy method to create a more optimal network. This redundancy method is a method that moves a network path when downtime occurs on one of the routers that are automatically changed to an active router and a standby router. In the implementation of the design using GNS3 software to create network topology and design. With the results of tests that have been carried out using the simulator, packet loss from using the HSRP method is at VLAN10 0.11\%, VLAN20 0.13\%, VLAN30 $0.30 \%$, VLAN40 $0.13 \%$, VLAN50 $0.22 \%$ AND VLAN60 0.16\%. So the purpose of research makes a network more optimal and flexible
\end{abstract}

Keywords: encapsulation; VLAN; HSRP; packet loss; routers

\begin{abstract}
Abstrak
Jaringan Local Area Network pada saat ini sering digunakan untuk meminimalkan suatu pekerjaan umum, segmentasi jaringan yang berbeda pada suatu gedung membutuhkan perhatian dalam merancang suatu jaringan yang memiliki trafik yang padat dan sering terjadi down serta vail over pada suatu alur jaringan, tentu membutuhkan performa jaringan yang optimal dan efesien, dengan cara encapsulation jaringan dengan satu alur dan membagi setiap segmentasi jaringan dengan VLAN. Tujuan dari penulisan ini yaitu menerapkan suatu desain dengan mengoptimalkan suatu jaringan menggunakan metode redudansi jaringan untuk membuat jaringan yang lebih optimal. Metode redudansi ini merupakan suatu metode yang memindahkan suatu alur jaringan apabila terjadinya down pada salah satu router yang diubah secara otomatis menjadi router aktif dan router standby. Dalam implemetasi desain tersebut menggunakan software GNS3 untuk membut suatu topologi dan desain jaringan. Dengan hasil pengujian yang telah dilakukan menggunakan simulator maka packet loss dari penggunaan metode HSRP adalah pada VLAN10 0.11\%, VLAN20 0.13\%, VLAN30 0.30\%, VLAN40 0.13\%, VLAN50 0.22\% dan VLAN60 $0.16 \%$. Sehingga tujuan dari penelitian membuat suatu jaringan lebih optimal dan fleksibel.
\end{abstract}

Kata kunci: encapsulation; VLAN; HSRP; packet loss; routers

(C) 2020 Jurnal JOINTECS

\section{Pendahuluan}

Perancangan jaringan $L A N$ yang digunakan pada bangunan gedung saat ini merupakan jaringan yang digunakan pada satu area gedung. Gedung sendiri memiliki beberapa segmentasi jaringan yang Maka dari itu untuk mengoptimalkan suatu digunakan untuk mengerjakan suatu pekerjaan yang jaringan dengan permasalahan seperti ini kita dapat berbeda-beda, dengan model gedung yang banyak menggunkan suatu metode pengembangan dari suatu segmentasi dan mengandalkan satu perangkat untuk mengirim suatu paket data kesetiap segmentasinya, mengakibatkan terjadinya permasalahan pada terjadi down dan vail over pada suatu alur jaringan.

Diterima Redaksi : 11-01-2020 | Selesai Revisi : 22-01-2020 | Diterbitkan Online : 26-01-2020 
jaringan local dengan menggunakan suatu redundancy dalam skema tersebut kedua router hanya encapsulation jaringan dan segmentasi VLAN untuk akan dibaca sebagai virtual router sehingga hanya akan membagi jaringan dengan menerapkan topologi tree terlihat menggunakan satu router saja, IP dan MAC pada gedung untuk mengatasi permasalahan perangkat address virtual dari dua router untuk merepresentasikan router yang sering terjadi down dengan trafik sebagai single defult gateway untuk semua host. pengiriman suatu data yang sangat banyak dengan pemusatan satu perangkat router, permasalahan ini dapat digunakan dengan menggunkan sebuah jaringan redudansi. Permasalahan ini terjadi dikarenakan kegagalan pada suatu perangkat yang terlalu banyak dilalui dengan beban satu jalur maka metode jaringan reduansi ini dapat digunakan karena jaringan redudansi ini dapat mengalihkan suatu jalur yang terpusat pada suatu perangkat router aktif kepada perangkat standby router. Penelitian ini bertujuan untuk mengimplementasi perancangan desain jaringan menggunakan aplikasi GNS3 yang merupakan aplikasi simulator jaringan yang digunakan untuk merancangan serta menganalisis encapsulation jaringan redudansi VLAN menggunakan metode HSRP (Hot Standby Router Protocol).

Pada perbandingan yang telah dilakukan dengan cara studi literatur pada jurnal sebelum-sebelumnya yang sudah diteliti. Pada penelitian ini menjelaskan tentang HSRP dan desain yang dapat mengkonfigurasi beberapa perangkat yang semuanya ada di subnet yang sama dan dapat bertindak sebagai gateway ke host di subnet. Redundansi dapat dikonfigurasi dengan mengkonfigurasi beberapa host untuk menggunakan satu gateway dan host lain untuk digunakan. Namun, jika salah satu dari gateway itu down, maka masih ada gateway yang standby [1]. Pada penelitian ini menjelaskan pengimplementasian HSRP dengan menggunakan topology tree pada topologi jaringan yang mengutamakan sebuah jaringan segmentasi hirarki pada model jaringannya [2]. Pada penelitian ini yang menjelaskan pengujian dengan penelitian jaringan redudansi menggunakan metode HSRP dan VVRP dengan rata-rata packet loss $2 \%$, software yang digunakan adalah GNS3 untuk membuat simulasi jaringan [3]-[4]. Pada penelitian ini yang menjelaskan pengujian jaringan redudansi menggunakan metode HSRP, software yang digunakan adalah cisco packet tracer untuk membuat suatu perancangan metode simulasi jaringan [5]. Pada penelitian ini yang menjelaskan pengujian performansi jaringan redudansi menggunakan metode $H S R P, V V R P$ dan GLBP. dengan rata-rata packet loss $2 \%, 0.80 \%$ dan $4 \%$ software yang digunakan adalah GNS3 [6]-[7]. Pada penelitian yang menerapkan simulasi jaringan redudansi menggunakan metode HSRP. Dengan topologi jaringan yang digunakan adalah topologi tree dan software yang digunakan adalah GNS3 [8].

Dalam sebuah perancangan dengan menggunakan metode tersebut mendapatkan sebuah solusi yang digunakan untuk mengatasi sebuah packet loss Pada sebuah jaringan, perangkat aktif yang bertanggung jawab atas penanganan lalu lintas ke alamat IP virtual, sedangkan tanggung jawab perangkat standby adalah untuk memantau perangkat aktif. Router standby akan mengambil alih tugas menangani alur yang dikirim ke alamat IP virtual dengan keduanya menerima lalu lintas ke IP alamat dan dengan mengambil alih MAC virtual alamat dengan menggunakan Protokol Resolusi Alamat (ARP) ketika router aktif akan gagal .

Adapun hal yang diamati adalah perangkat apa saja yang digunakan, sejauh mana manfaatan jaringan yang digunakan serta kendala yang muncul pada topologi jaringan yang saat ini sedang berjalan. Hasil dari analisa fase awal ini akan dijadikan sebagai dasar untuk memetakan solusi yang dapat diambil untuk memecahkan masalah dalam jaringan yang sedang berjalan [9].

\subsection{Proses Encapsulation}

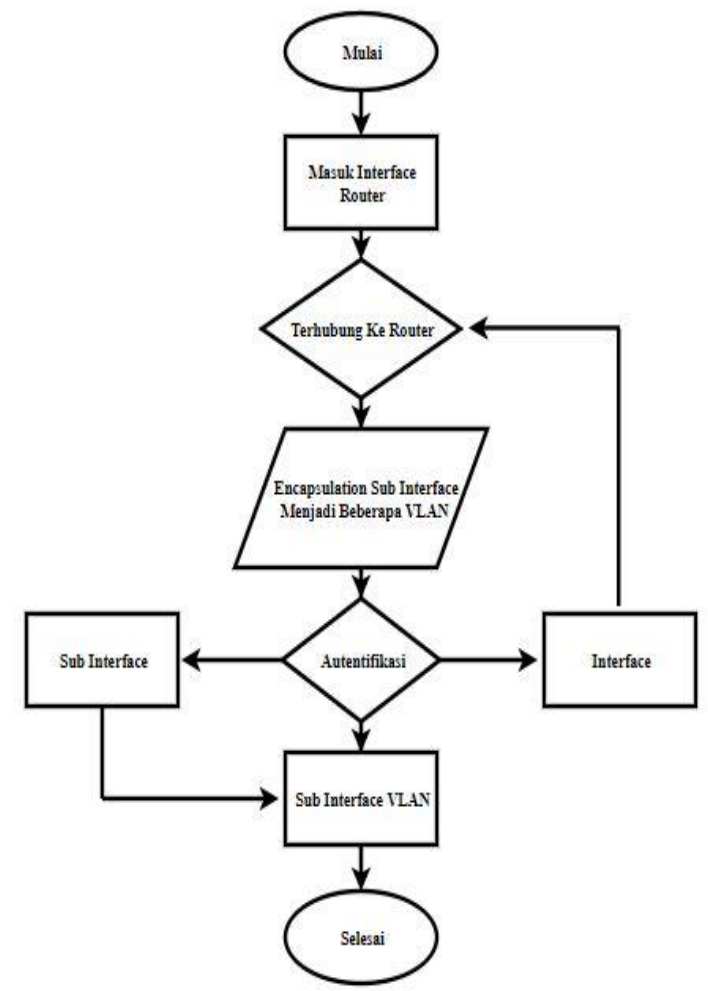

Gambar 1. Flowchart Proses Encapsulation Jaringan

\section{Metode Penelitian}

Pada Gambar 1, alur dari encapsulation paket data Hot Standby Routing Protocol (HSRP) Merupakan pada suatu jaringan merupakan protokol interface yang protocol yang dapat mengantisipasi kegagalan gateway dapat membawa lebih dari satu jenis protocol, pada jaringan, protokol ini membuat gateway virtual sebagai segmentasi jaringan dengan merubah suatu interface

(JOINTECS) Journal of Information Technology and Computer Science Vol 5 No. 1 (2020) 49 - 54 
menjadi sebuah sub interface untuk di encapsulation melakukan pengelolaan dan juaga menyediakan prosedur menjadi sebuah paket bersistem pengalamatan ip pada pengiriman lalu lintas data dalam jaringan, layer suatu segmentasi jaringan [10].

\subsection{Proses Kerja Metode HSRP}

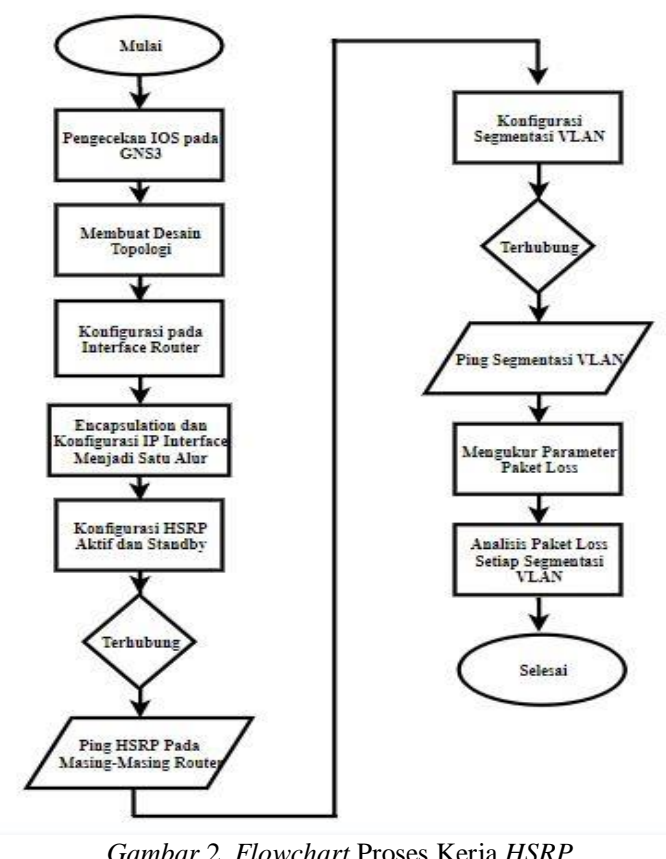

Berdasarkan Gambar 2, proses flowchart encapsulation jaringan digunakan untuk membuat satu alur jaringan menjadi lebih efesien, pembagian segmentasi pada suatu vlan untuk membuat alur jaringan menjadi lebih kompleks.

Metode HSRP digunakan untuk menurunkan paket loss atau vail over pada suatu jaringan, penelitian yang sudah disusun dengan pencarian permasalahan yang diangkat dapat disimpulkan menjadi suatu saran untuk meningkatkan penelitian ini [11].

\subsection{Kebutuhan Perancangan Jaringan}

Meliputi beberapa jenis perangkat yang digunakan dan penelitian:

1. Tools : HSRP (Hot Standby Router Protokol), EIGRP, Encapsulation, dan vlan.

2. Software : VPCS (PC), C3725(Router), IOSVL (Switch), Kabel UTP, GNS3 (Simulator), dan Wireshark.

3. Hardware : Laptop Windows 10, Processor AMD Fx, Ram DDR3i 12GB, HDD 1 Terabyte.

\subsection{Topologi Desain}

Hasil dari analisa pada fase pertama dengan pencarian studi literatur, penelitian dan observasi. Selanjutnya pada fase kedua menentukan desain dan metode jaringan yang sudah dipetakan. Pada Gambar 3, topologi ini terdiri dari 2 buah model layer yaitu layer data link dan Layer network, layer data link berfungsi untuk network berfungsi dalam melakukan pengalamatan logis dan pemetaan paket routing pada jaringan. Pada topologi saat ini jaringan bekerja menggunakan 2 buah router untuk melakukan suatu redudansi pada jaringan yang akan dibuat. Pada host tersebut dikonfigurasi virtual gateway host akan mengakses server dengan melewati jalur R1. Bila jalur melalui R1 gagal, R2 akan bertindak sebagai main gateway. Dalam kondsi ini, bila jalur R1 sudah pulih, secara otomatis R1 kembali menjadi aktif dan R2 mejadi standby [12].

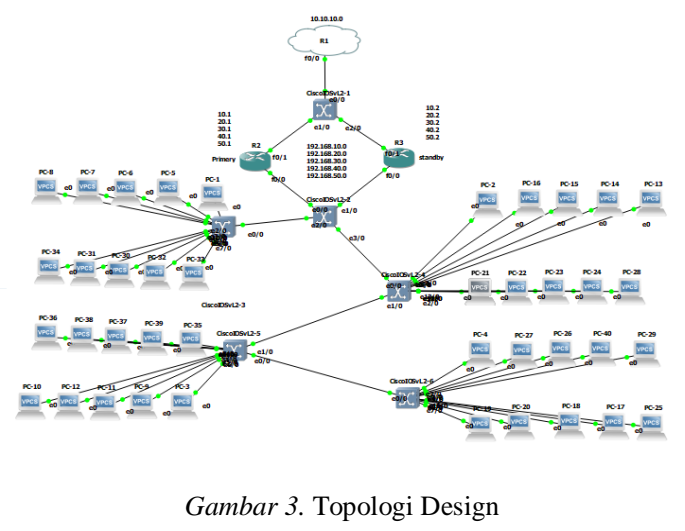

\subsection{Segmentasi VLAN}

Pada Tabel 1, topologi jaringan yang dirancang akan menerapkan VLAN yang bertujuan untuk melakukan segmentasi alamat IP host sesuai segmentasi dalam perancangan jaringan [13]. Berikut ini adalah data VLAN dengan segmentasi alamat IP yang akan digunakan .

Tabel 1. Segmentasi Vlan dan Perancangan

\begin{tabular}{ccc}
\hline No & VLAN & IP Address \\
\hline 1 & 10 & $192.168 .10 .4-254$ \\
\hline 2 & 20 & $192.168 .20 .4-254$ \\
\hline 3 & 30 & $192.168 .30 .4-254$ \\
\hline 4 & 40 & $192.168 .40 .4-254$ \\
\hline 5 & 50 & $192.168 .50 .4-254$ \\
\hline
\end{tabular}

\subsection{Perancangan $H S R P$}

Untuk menjamin koneksi antar segmen tahan terhadap gangguan, maka topologi jaringan yang dirancang akan menerapkan metode $H S R P$ yang memiliki banyak jalur redundansi. Terdapat satu buah multilayer switch pada core layer dan dua buah multilayer switch yang bekerja pada distribution layer, di mana beberapa port akan berada pada keadaan standby sedangkan port lainnya aktif. Apabila pada port yang aktif mengalami gangguan seperti kabel terputus atau tidak tersambung dengan benar, maka port pada multilayer switch lainnya yang dalam mode standby akan aktif. Untuk lebih jelasnya mengenai Status port pada masing masing switch.

(JOINTECS) Journal of Information Technology and Computer Science Vol. 5 No. 1 (2020) 49 - 54 
Hendy Dwi Haryoyudhanto, Iskandar Fitri, Andri Aningsih

(JOINTECS) Journal of Information Technology and Computer Science Vol. 5 No. 1 (2020) 49 - 54

Tabel 2. Perancangan IP Router 1

ISP

\begin{tabular}{rrrrr} 
Port & IP & Status & Priority & \\
\hline F0/1 & 10.10 .10 .1 & Aktif & 200 \\
\hline
\end{tabular}

Pada Tabel 2, diatas ini adalah tabel penggunaan port beserta statusnya merupakan sebuah perancangan pengelamatan ip untuk router 1 .

Tabel 3. Perancangan IP HSRP Pada Router 2

\begin{tabular}{cccc}
\hline \multicolumn{3}{c}{ Router 1 } & \\
Port & IP & Status & Priority \\
\hline F0/1 & 10.10 .10 .2 & Aktif & 200 \\
F0/0.10 & 192.168 .10 .1 & Standby & 200 \\
F0/0.20 & 192.168 .20 .1 & Standby & 200 \\
F0/0.30 & 192.168 .30 .1 & Standby & 200 \\
F0/0.40 & 192.168 .40 .1 & Standby & 200 \\
F0/0.50 & 192.168 .50 .1 & Standby & 200 \\
F0/0.60 & 192.168 .60 .1 & Standby & 200 \\
\hline
\end{tabular}

Pada Tabel 3, diatas ini adalah tabel penggunaan port beserta statusnya merupakan sebuah perancangan pengelamatan ip untuk router 2 dan encapsulation pada salah satu interface menjadi beberapa sub interface.

Tabel 4. Perancangan IP HSRP Pada Router 3

\begin{tabular}{cccc}
\hline & \multicolumn{3}{c}{ Router 2} \\
Port & IP & Status & Priority \\
\hline F0/1 & 10.10 .10 .3 & Aktif & 100 \\
F0/0.10 & 192.168 .10 .1 & Aktif & 100 \\
F0/0.20 & 192.168 .20 .1 & Aktif & 100 \\
F0/0.30 & 192.168 .30 .1 & Aktif & 100 \\
F0/0.40 & 192.168 .40 .1 & Aktif & 100 \\
F0/0.50 & 192.168 .50 .1 & Aktif & 100 \\
F0/0.60 & 192.168 .60 .1 & Aktif & 100 \\
\hline
\end{tabular}

Pada Tabel 4, diatas ini adalah tabel penggunaan port beserta statusnya merupakan sebuah perancangan pengelamatan ip untuk router 2 dan encapsulation pada salah satu interface menjadi beberapa sub interface.

\section{Hasil dan Pembahasan}

Untuk menjamin bahwa rancangan yang diusulkan dapat memenuhi ekspektasi pengguna serta mengatasi masalah yang ada pada jaringan sebelumnya maka dilakukan beberapa pengujian:
1. Pengujian encapsulation pada HSRP

Encapsulation pada jaringan yang terdapat pada suatu interface router dapat dilakukan dengan cara mengencap pada salah satu interface.

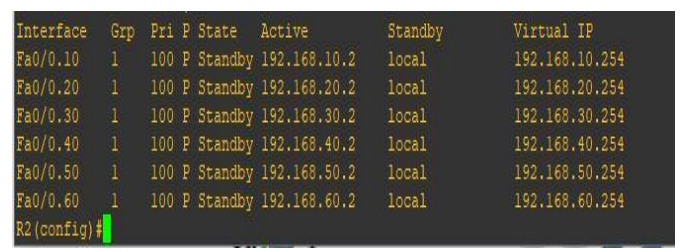

Gambar 4. Pengujian Avilability HSRP Standby pada

$$
\text { Router1 }
$$

Pada Gambar 4, diatas merupakan suatu hasil dari encapsulation jaringan pada suatu router 1 pada suatu interface yang dibagi menjadi beberapa sub interface dalam pengalamatan IP menjadi standby.

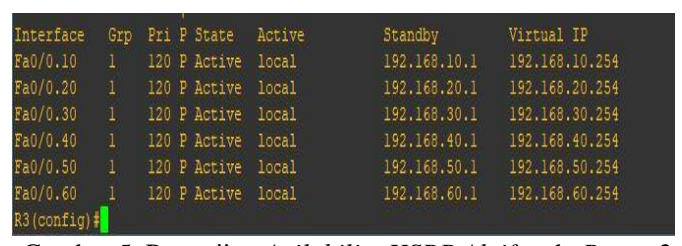

Gambar 5. Pengujian Avilability HSRP Aktif pada Router2

Pada Gambar 5, diatas merupakan suatu hasil dari encapsulation jaringan pada suatu router 2 pada suatu interface yang dibagi menjadi beberapa sub interface dalam pengalamatan IP menjadi active.

2. Pengujian Hot Standby Router Protocol

Selanjutnya ketika jalur utama terputus maka jaringan harus secara otomatis memindahkan lalu lintas jaringan melalui jalur standby.

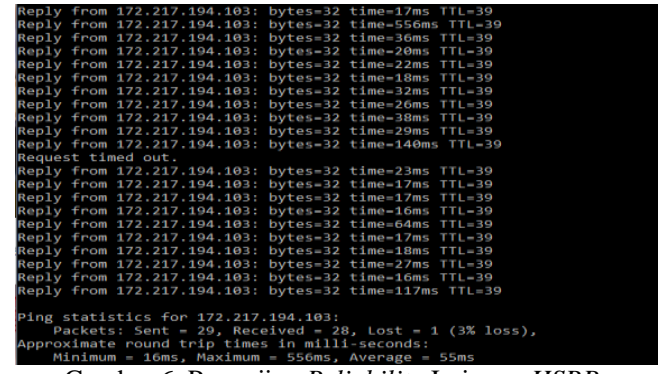

Gambar 6. Pengujian Reliability Jaringan HSRP

Pengujian HSRP pada Gambar 6, untuk menguji apakah pemindahan jalur dari jalur utama ke jalur standby berlangsung secara otomatis bila terjadi request time out. Hal ini penting untuk menjamin tersedianya akses ke jaringan secara utuh tanpa perlu adanya campur tangan pemindahan secara manual dapat meningkatkan packetloss.

3. Standar Parameter Packet Loss

(JOINTECS) Journal of Information Technology and Computer Science Vol. 5 No. 1 (2020) 49 - 54 
Penyesuaian pengujian Packet Loss yang sesuai dengan acuan perhitungan qos, menjelaskan hasil dari perhitungan jumlah dari paket yang hilang dapat terjadi karena benturan paket dan vail over pada suatu jalur. Pada jaringan terdapat parameter yang sudah di uji dengan pengujian standar jaringan melalui perhitungan qos agar dapat mengetahui hasi standar dari packet loss, di suatu jaringan redudansi menunjukan bahwa $0 \%$ low, $3 \%$ medium, $15 \%$ high dan $25 \%$ over melihat dari standar parameter bahwa semakin kecilnya persenan pada perhitungan qos untuk packet loss, maka menurunnya vail over yang terjadi pada suatu jaringan menjadi lebih optimal [13]-[14].

\section{Hasil Pengujian Parameter Packet Loss}

Setelah dilakukan pengujian secara Avilability dan reliability pada jaringan HSRP pada Gambar 7, diagram dibawah menujukan pada pengujian suatu packet loss pada masingmasing segmentasi pengujian yang dilakukan disetiap VLAN dapat disimpulkan pada penelitian ini berdasarkan data yang telah didapat rata-rata dari packet loss pada setiap VLAN adalah $0,17 \%$ menunjukan bahwa packet loss yang terjadi adalah low dengan mengacu kepada standar perhitungan qos.

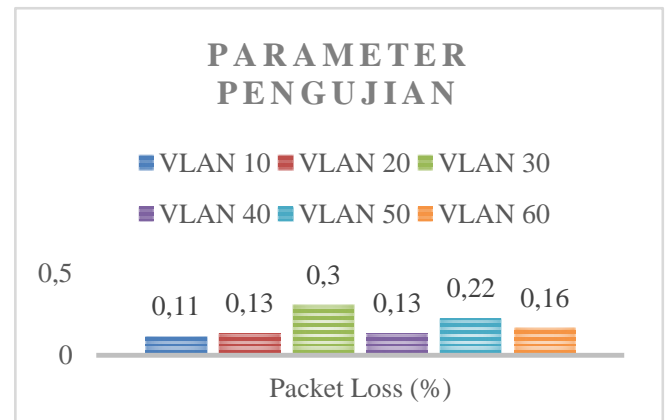

Gambar 7. Diagram Parameter Hasil Pengujian Packet Loss

\section{Kesimpulan}

Berdasarkan hasil yang didapat maka dapat disimpulkan pada sistem perancangan yang telah dibuat dengan menambahkan suatu tools pada suatu layer data link untuk membuat suatu segmentasi VLAN pada switch agar alur pada suatu jaringan dapat teratur, pada akses layer network menambahkan suatu tools atau metode HSRP sehingga kinerja dari suatu layer network dapat lebih optimal apabila terjadi down pada suatu jaringan dan meningkatkan suatu availability pada setiap layer.

\section{Daftar Pustaka}

[1] P. Kaur, H. Kaur, and J. Kaur, "Hot Standby Routing Protocol ( HSRP ),” vol. 3, no. 1, pp.
2110-2112, 2017.

[2] W. Purwanto and S. Risnanto, "Implementasi metode hsrp pada bank jawa barat dan banten kantor wilayah i dan kcp simpang dago," vol. 3, no. $1,2018$.

[3] P. Firmansyah, Wahyudi, M \& Rachmat, "Analisis Perbandingan Kinerja Jaringan CISCO Virtual Router Redundancy Protocol (VRRP) Dan CISCO Hot Standby Router Protocol (HSRP)," Tek. Komput. AMIK BSI Tegal, vol. 1, no. 1, pp. 764-769, 2018.

[4] M. Y. Choirullah, M. Anif, and A. Rochadi, "Analisis Kualitas Layanan Virtual Router Redundancy Protocol Menggunakan Mikrotik pada Jaringan VLAN," J. Nas. Tek. Elektro dan Teknol. Inf., vol. 5, no. 4, pp. 278-285, 2016.

[5] O. K. Sulaiman, M. Ihwani, and M. Basri, "Model Hierarki Network dengan Menggunakan Spanning Tree Protocol (STP) dan Hot Standby Router Protocol (HSRP)," Semin. Sehari Progr. Pascasarj. Inform., vol. 1, no. 1, pp. 42-46, 2015.

[6] I. G. M. S. B. Pracasitaram, N. P. Sastra, and N. D. Wirastuti, "Performansi Jaringan TCP/IP Menggunakan Metode VRRP, HSRP, dan GLBP," Maj. Ilm. Teknol. Elektro, vol. 18, no. 1, p. 77, 2019.

[7] A. Akmaludin, A. Mt, S. U. Masruroh, and M. Sc, "Evalusi Kinerja Hot Standby Router Protocol ( HSRP ) dan Gateway Load Balancing Protocol ( GLBP ) untuk Layanan Video Streaming," vol. 2, no. 1, pp. 43-51, 2019.

[8] S. V Suji and G. Sekar, "Design and Implementation of Secured HSRP Protocol using VLAN," vol. 2, no. 1, pp. 2014-2016, 2015.

[9] O. K. Sulaiman, "Simulasi Perancangan Sistem Jaringan Inter Vlan Routing di Universitas Negeri Medan," CESS (Journal Comput. Eng. Syst. Sci., vol. 2, no. 3, pp. 92-96, 2017.

[10] I. Warman and A. Hanafi, "Analisa Perbandingan Kinerja Generic Routing Encapsulation (GRE) Tunnel Dengan Point to Point Protocol over Ethernet (PPPoE) Tunnel Mikrotik Routeros," vol. 7, no. 1, pp. 58-66, 2019.

[11] C. V. Ravikumar, Y. M. Srikanth, P. Sairam, M. Sundeep, K. P. Bagadi, and V. Annepu, "Performance analysis of HSRP in provisioning layer-3 gateway redundancy for corporate networks," Indian J. Sci. Technol., vol. 9, no. 20, pp. 2-6, 2016.

[12] A. P. Wahyu, "Optimasi Jaringan Local Area Network Menggunakan VLAN dan VOIP," $J$. Inform. Pengemb. IT, vol. 2, no. 1, pp. 54-57, 2017.

[13] M. Fahri, A. Fiade, and H. B. Suseno, "Simulasi Jaringan Virtual Local Area Network (VLAN) Menggunakan Pox Controller," J. Tek. Inform., vol. 10, no. 1, pp. 85-90, 2018.

[14] R. Wulandari, "ANALISIS QoS (QUALITY OF SERVICE) PADA JARINGAN INTERNET

(JOINTECS) Journal of Information Technology and Computer Science Vol. 5 No. 1 (2020) 49 - 54 
Hendy Dwi Haryoyudhanto, Iskandar Fitri, Andri Aningsih

(JOINTECS) Journal of Information Technology and Computer Science Vol. 5 No. 1 (2020) 49 - 54

(STUDI KASUS: UPT LOKA UJI TEKNIK

PENAMBANGAN JAMPANG KULON

LIPI)," J. Tek. Inform. dan Sist. Inf., vol. 2, no. 2, pp. 162-172, 2016.

[15] R. Tulloh, "Analisis Performansi Agregasi Link dengan Lacp pada SDN menggunakan RYU sebagai Controller," J. Nas. Tek. Elektro, vol. 6, no. 3, p. 203, 2017. 